INTERNATIONAL HIGHER EDUCATION, Number 72. Summer 2013

Page 15-16

\title{
Getting Value for Money in Higher Education
}

\author{
PHILIP G. ALTBACH and PAWAN AGARWAL
}

Philip G. Altbach is professor and director of the Center for International Higher Education, Boston College. E-mail: altbach@bc.edu. Pawan Agarwal is advisor for higher education, the Planning Commission, Government of India. E-mail: apawan08@gmail.com.

Although Indian higher education suffers from many dysfunctionalities and the system overall is characterized by "pinnacles of excellence in a sea of mediocrity" - by some international comparisons, India does reasonably well. Here are a few examples:

- India is a global leader in terms of GDP spent by public and private sources on higher education. India devotes a very high proportion of its national wealth of higher education. At 3 percent of the GDP (1.2\% from public and 1.8\% from private sources), Indian spends more than what the United States (1.0\% public and $1.6 \%$ private) or Korea ( $0.7 \%$ public and $1.9 \%$ private) spends on higher education. This suggests a limited scope for further increase, although more is required since in absolute figures investment in higher education does not measure up in international terms. Further, there is an urgent need for effective and efficient use of funds, in order to promote both equity and excellence.

- India's gross enrollment rate, 18 percent, the proportion of the age group accessing higher education, is among the highest of countries at India's level of 
development. This is particularly impressive given India's size and complexity. The recently approved 12th Five-Year Plan aims at raising the gross enrollment rate to 25 percent by 2017 and is both desirable and achievable.

- Finally, academic salaries, when measured against other countries by accurate purchasing power parity comparisons, are quite good. Among 28 countries in a recent study, India ranked fourth from the top in entry salaries for academics-and better than the other BRIC (Brazil, Russia, India, and China) nations. China scored near the bottom for average salaries. This good showing is the result of the major pay increase implemented in 2006.

\section{VALUE FOR MONEY?}

Is India gaining value for its investment in higher education? Also, is more money the answer to the challenges? Most observers would agree that on average Indian colleges and universities do not produce a very distinguished job and are definitely not "world class." A number of factors are related to the positive trends noted here. Although India invests significant sums in postsecondary education, with the funds increasingly coming from students and their families, it does not spend effectively. There is little coordination between the states and the central government.

Many of India's 34,000 undergraduate colleges are too small to be viable. They are generally understaffed and ill-equipped; two-thirds do not even satisfy government-established minimum norms, and they are unable to innovate because of the rigid bureaucracy of the affiliating system that links the colleges to a supervising university. All this makes the system highly fragmented, scattered and difficult to manage. There is a strong case for consolidation and merging 
small institutions. But the affiliating system is vast and deep-rooted and, therefore, is neither feasible nor desirable to dismantle it. However, decentralization of part of the curriculum holds great promise. With greater academic autonomy, the core courses could be retained by the university, while the responsibility for the rest of the curriculum could be devolved to the colleges. This would create a desired innovation culture in the colleges. Clustering and even merging colleges that are very small would also have to figure into this reform. In addition, universities that affiliate a large number of colleges would need to be reorganized into two or more universities, with each of them affiliating a smaller number of colleges-in order to improve overall academic effectiveness.

While gross enrollment rates are not bad by relevant international standards, India, however, is about four decades behind most advanced nations in enrollments. While the United States had an enrollment rate of 15 percent by the 1940s, most advanced nations reached that stage several decades later. The United Kingdom, Australia, France, and Japan had enrollment rates of 18, 23, 24, and 25 percent in 1975; and Korea enrolled only 8 percent in 1975, which rose to 13 percent in 1980, and then rapidly rose to 34 percent in 1985. All these countries have achieved a system close to universal higher education; but it must be recognized that enrollments have grown hand in hand, based on the rise in demand for qualified people with agriculture contributing to less than 5 percent of the workforce. Considering that over half of the people in India are still engaged in the farm sector with limited need for higher qualifications, current levels of enrollment in India appear to be adequate. The bigger challenge is that the students do not 
choose to study in fields that will best contribute to economic growth-or to their own job prospects. Also, employers regularly complain that graduates are not adequately for available jobs.

While it is true that Indian academics, by international comparisons, are relatively well paid, they are not necessarily effective. Academics, and especially college teachers, are constrained by rigid bureaucracy. Further, their work is not carefully evaluated-salary increases and promotions are awarded rather on the basis of seniority. Unfortunately, when salaries were increased in 2006, this boon was not accompanied by any reforms in the teaching profession or requirements for evaluation. A System of Academic Performance Indicators for promotion and appointment of professors and lecturers is yet to take roots. It appears that Indian academics want to do a good job and most are committed to their profession-structural impediments and an ossified culture get in the way.

Our general impression is that despite several areas in which India compares well, globally, deep structural and cultural impediments constrain the academic system as a while from performing effectively.

\section{CONCLUSION}

India has achieved some areas of accomplishment in higher education. The challenge is to capitalize on these plans and reform an ossified system. In the Indian case, expenditure does not necessarily mean effectiveness. In this way, Indian higher education may be compared to the American health care system. The United States spends the most per capita on health care, but expenditure does not yield results. The Obama reforms, like the 12th Plan India, may finally improve an ossified system traditionally dominated by special interest and 
conflicts between the federal government and the states. The recently approved 12th Plan provides a good framework for change. It seeks to align central government investment with that of the state governments-align new capacity with demand. It also seeks to create a performance culture through deepening of competitive grants and creation of related institutional arrangements. However, success depends on effective implementation. 